(C) <2018>. This manuscript version is made available under the CC-BY-NC-ND 4.0 license http://creativecommons.org/licenses/by-nc-nd/4.0/

The definitive publisher version is available online at 10.1016/j.midw.2018.02.007 


\section{Introducing sensitive issues and self-care strategies to first year midwifery students.}

\section{Introduction}

First year midwifery students learn early in their first semester about situations in midwifery where a high level of emotion is expressed. They are exposed to the intimate nature of midwifery work such as taking a sexual history, being faced with the body image changes of pregnancy and working with women in the extreme pain of labor. Students are also required to engage in continuity of care experiences where the student develops a relationship of trust with a woman. First year midwifery students are introduced to all these types of topics within the early weeks of their course. Such sensitive issues have the potential to trigger emotional distress for the students. This may lead to students' inability or reluctance to discuss complex and personal issues with each other in the classroom and then later with women when on clinical practice.

\section{Background}

Midwifery students come from a diverse background including those who have just finished secondary school (school leavers) and those who are older and have a previous career working in another unrelated industry or completed previous study in an unrelated area (mature age) students. School leavers often consider a midwifery career after witnessing midwifery care for friends and relatives or hearing their birth stories (Cullen et al. 2016). These younger midwifery students are also exposed to midwifery through reality television and many have a desire to work with babies (Cullen et al. 2016). Mature age students have reported personal experience with childbirth, either as a mother or professionally, such as working as a doula; others have been members of maternity consumer organisations (Carolan \& Kruger 2011b; Cullen et al. 2016; Fraser \& Hughes 2009). Both school leavers and mature age students have an attraction to midwifery based on their preconceived ideas of the role and scope of the profession of midwifery. These ideas are often of an altruistic nature; students want to be part of a caring profession and make a positive difference to women's lives during childbirth. Overall, midwifery is portrayed as a satisfying career (Carolan \& Kruger 2011a; Carolan \& Kruger 2011b; Fraser \& Hughes 2009; Williams 2009). Commencing students usually have not had exposure to the realities of studying and working in midwifery, and often have an idealised view of the midwifery. 
Students may begin midwifery studies with the view that pregnancy and birth are overwhelmingly joyful and happy events for women and their families and they expect to share in this joy. Younger students view pregnancy, birth and motherhood as natural positive life-changing events; this construct is particularly articulated by non-mothers (Fraser \& Hughes 2009). There is a belief from undergraduate students, undertaking science degrees in preparation for nursing or medicine that birth can be risky and most students believe women should have a baby in hospital. These views are influenced by the depiction of childbirth in the media (DeJoy 2010; Fraser \& Hughes 2009). Midwifery students believe they can support women to have a positive birth experience through creating a caring compassionate environment in the hospital setting (Fraser \& Hughes 2009; Seibold 2005). These idealised notions are a challenge for educators when faced with the reality of undertaking midwifery that requires intense study, clinical practical experience in often busy understaffed birth units and a high level of emotional work (Fraser \& Hughes 2009; Hunter 2001).

The high level of emotion midwives experience during their work is due to the sensitive, complex and varied nature of midwifery. It involves the acknowledgement of sexuality, being with women in labour who are experiencing intense pain and the organisation of midwifery care (Hunter 2001). A midwifery degree requirement includes continuity of care experiences in addition to rostered clinical shifts throughout the maternity ward. Continuity of care experiences require the student to develop a relationship of trust with women through pregnancy, be on call for her birth and provide care in the early parenting period. The continuity of care experiences together with the division of labour in the hospital wards can result in an additional emotional load (Hunter 2001). Midwifery students are expected to address all of these issues in their first year of study at university and may feel overwhelmed leading to high levels of attrition (Carolan \& Kruger 2011b).

Reasons students leave within the first six months of their midwifery degree include a lack of support in clinical practice, the emotional demands of midwifery and balancing study and other life demands (Gray et al. 2012; Green \& Baird 2009). A strong network of peers provides support and a safe environment for midwifery students to reflect on their clinical experiences (Sidebotham et al. 2015). We have previously addressed the issue of "culture shock" in clinical placement through a first year workshop that has been embedded into the curriculum (Cummins et al. 2014). However we recognise there is a need to address other factors that cause student attrition. 
Students desire a sense of connectedness to lecturers and other students. There is scope for tutor-mediated support, peer-to-peer support, counselling services and nurturing interventions to support first year midwifery students to stay in the profession (Carolan \& Kruger 2011b; Green \& Baird 2009). It has been suggested that midwifery students would benefit from reflecting critically on their own concept of midwifery, early in their degree, so they are better equipped to deal with the different experiences they have during study and clinical practise (Fraser \& Hughes 2009). To address this we decided to develop a further two workshops with the aim of equipping students with personal and professional tools with which to discuss sensitive issues in midwifery and develop tools for self-care.

The two workshops developed provided students with an opportunity to explore and reflect on their own backgrounds, engage early with their cohort, obtain a formative experience in the discussion and digestion of sensitive issues relating to their profession, and begin to prepare them for their first year of midwifery studies. The workshops also aimed to promote self-care strategies to support students in their transition to becoming a midwifery student. Ethical approval was granted by the university ethics committee: UTS HREC REF NO. 2015000101.

\section{Methods}

The first workshop introduced students to sensitive topics in midwifery and was run in the first class of semester before the students' clinical placement in hospitals. This workshop was facilitated by an experienced midwifery lecturer with a strong clinical background who has experience in first year projects. The second workshop focused on self-care strategies and was run later in semester following the students' clinical placement. The second workshop was facilitated by a professional who has experience in mindfulness and life coaching. A midwifery lecturer attended and was provided with skills and strategies for running this workshop in the next year in order to embed the workshop into the first year experience. For each workshop, quantitative and qualitative data were collected pre and post workshops using a survey.

\section{Description of the workshops}

The first workshop had a dual aim of introducing the students to some sensitive issues in midwifery education/practice and secondly to begin to identify the students' support systems should the content cause them emotional distress. The workshop opened with 
an introduction to the concept of a safe, non-threatening environment to encourage students to discover their own beliefs and preconceptions. Green and Baird (2009) proposed students could benefit from professional counselling services therefore we informed students that professional counselling services were available on campus, free of charge, should the content of the workshop cause them distress.

\section{First workshop}

\section{Getting to know each other}

The first activity focused on meeting new people. Students were divided into groups based on where they lived by train lines. The purpose of this activity was for students to meet new people that they could travel to and from home together. After the students were grouped by train/bus line they engaged in a well-known team building activity called the human knot. Each group stands in a tight circle and the participants place their hands into the centre with closed eyes. Each hand must link with another hand. Once everyone is holding two other hands they open their eyes. The group must untie the knot and make a circle without letting go of each other. The activity is designed to build trust and prepares the students for the next activity.

\section{Sensitive issues in midwifery practice}

The next activity involved groups of students discussing emotions and where to find personal and professional support when needed. The students were briefed that photographs and video footage were to be used to encourage thoughts of how to manage their feelings. Within the groups students were asked to discuss their feelings regarding words, phrases and conditions that they would encounter during midwifery practice. These included: domestic violence, sexual history, sexual abuse, HIV, hepatitis $\mathrm{B}$ and $\mathrm{C}$, miscarriage, abortion, stillbirth, twins and forceps. The students were then asked to consider their emotions after being shown images of a naked pregnant woman labouring in the shower and another naked woman lying on the bed with her leg elevated in preparation for birth. Next the students watched and listened to a woman in labour in a video clip making very loud, sexual sounding noises. Both the images and the sounds were purposefully chosen to provoke uncomfortable feelings for the participants, with an aim to initiate discussion in the groups. Again in their groups the students discussed ways they could manage the feelings these activities provoked. The final activity asked the students to name three ways to find support for the way the videos and images made them feel. The workshop concluded with a relaxation activity, a body scan meditation exercise. 


\section{Second Workshop}

\section{Self-care strategies}

The second workshop focused on self-care strategies and was run later in semester to identify how students were managing the feelings elicited from the first workshop and their first clinical experiences. The aim was to facilitate the students to develop skills that cultivate wellness, hope, resilience and flourishing (Yu 2014) and provide time for the students to practise mindfulness and relaxation techniques. Mindfulness has been found to be feasible in reducing stress for midwives and nurses in the workplace (Foureur et al. 2013) and in student wellbeing (van der Riet et al. 2015). Another positive psychology model for human flourishing was also incorporated into the workshop. The framework included positive emotion (P), engagement (E), relationship (R), meaning (M) and accomplishment (A), (PERMA) (Kern et al. 2015). Students were introduced to mindfulness techniques and the PERMA model in the second workshop.

\section{Survey instrument used}

For each workshop, students completed a pre and post-workshop survey, developed by the first author. Each survey gathered quantitative data using 5-point Likert scales and included the same questions both before and after each workshop. Likert scales are widely used to measure attitudes and opinions with respondents indicating their level of agreement or disagreement (Minichiello et al. 2004). In addition to the quantitative data, each post-workshop survey also included open-ended questions to gain further insight on the students' perception of each workshop.

The surveys administered in first workshop about 'sensitive issues in midwifery' (Box 1) contained 8 quantitative questions to gauge how "comfortable" students felt about a range of sensitive issues in midwifery. The post-workshop survey also contained two qualitative questions, 'What was the most useful aspect of this session?' and 'What did you find valuable about discussing the sensitive topics, images and video clip?' Usefulness indicates how the workshop can be used for practical purposes while the value question reflects the students' personal benefit from the workshop.

The surveys in the second workshop, 'fostering self-care and mindfulness' (Box 2) contained 5 quantitative questions on how "confident and knowledgeable" the students' felt before and after the workshop. In addition, the post-workshop survey contained two qualitative questions, 'What was the most useful aspect of this session?' and 'How will you incorporate the strategies discussed in this workshop in your own personal professional life?' 
Both pre and post surveys from both workshops were de-identified and paired using the student identification number. The cases where no paired samples were found were excluded from the quantitative analysis.

\section{Sample}

The sample consisted of 53 first year undergraduate midwifery students who all participated in the workshops. The option to evaluate the workshop was voluntary. № demographic information about the students was collected as the workshop was held in the first class in the first year. It was deemed inappropriate to collect demographic information as the students may not be open to participating if they thought we could identify their responses.

\section{Analysis}

Quantitative analysis was performed using RStudio version 0.98.1074. A one-sided paired t-test was performed on the data for each workshop to determine whether each response from the post-workshop survey was significantly greater than the response for the same question in the pre-workshop survey.

Qualitative survey data were typed into a Microsoft Word document and content analysis was performed on the data using NVivo for Mac Version 10.2.1. Content analysis is a qualitative method for identifying patterns in textual material, involving systematically counting the number of times the categories occur (Minichiello et al. 2004). An initial list of categories was developed and coded for each workshop. Matches were categorised to include stemmed words, for example "Talk" includes "Talking". Categories were added during the coding process, with the previously coded data reviewed and recoded each time a category was added. The coding was reviewed by the other three authors to arrive at the final categories as listed in the results section.

\section{Results}

From the first workshop there were 36 matched pairs in the sample able to be used in the quantitative analysis and 40 post-workshop surveys containing the qualitative questions. The second workshop had 16 matched pairs and 30 post-workshop surveys. Fewer students answered the surveys in the second workshop, and there were a greater number of surveys where a matched pair could not be found because the student number was not provided. 


\section{The first workshop: 'Sensitive issues in Midwifery Practice'}

\section{Quantitative results:}

The results from the first workshop found a significant increase $(p<0.05)$ for all questions except the final question, 'How comfortable do you feel undertaking a relaxation exercise in a group?' This question had the highest pre-workshop mean (4.47) indicating that students were already comfortable with undertaking relaxation activities in a group, so the workshop did not significantly increase this high level of comfort. The largest increase in comfort levels was 'With finding new personal and professional emotional and psychological supports', followed by 'Talking to women about sensitive topics such as: Abortion, miscarriage, sexuality, sexually transmitted diseases, normal birth and caesarean section birth' and 'With meeting new people in a new environment'. The results are presented in table 1.

Insert table 1

\section{Qualitative results:}

There were 35 responses coded as useful, with 32 responses recorded in response to the valuable question. The qualitative results for the first workshop led to ten categories being developed. In descending order of frequency of response these categories were: 'Discussion', 'Opinions', 'Meeting new people', 'Normalising', 'Feelings', 'Confronting', 'Support', 'Comfortable' and 'Learning'. Categories were not mutually exclusive. In response to the first open-ended question on the post-workshop survey 'What was the most useful aspect of this session?' the most frequently cited useful aspects of the first workshop were the social aspects of meeting new people and discussing topics with other students. In response to the second open-ended question, 'what did you find valuable about discussing the sensitive topics, images and video clip?' students cited sharing the opinions of others, sharing their feelings about the topic and normalising their experiences as the most valuable aspects gained.

\section{Having a discussion}

Data were coded as discussion where the respondent referenced discussion, talking or listening. There were 23 responses coded as discussion, 15 mentioned discussion in response to the question 'What was the most useful aspect of the session?' Seven responses were recorded as explicitly mentioning discussion for the question 'What did you find valuable about discussing the sensitive topics, images and video clip?' To gain further insight into the topics, discussion was analysed against the other nine categories to determine the frequency of response for the other categories. Normalising 
experiences and meeting new people were the most frequent discussion topics. Discussing confronting topics, being exposed to different opinions, and realising that others shared the same feelings were also discussed by students. Each category is presented in Table 2 along with some quotes to illustrate the voices of participants

Insert Table 2

\section{Second workshop: 'Fostering self-care and mindfulness in midwifery practice'}

\section{Quantitative results:}

The second workshop found statistically significant $(\mathrm{p}<0.05)$ differences between responses for pre and post-workshop for all 5 questions. The largest increase was for 'Accessing self-care strategies in your personal and professional life' and 'Trying out new self-care strategies for your personal and professional life' followed by 'Undertaking a relaxation exercise in a group'. The results are presented in table 2

\section{Insert table 3}

\section{Qualitative results:}

Responses for the open-ended question, 'What was the most useful aspect of this session?' were coded as 'useful'. Responses for the open-ended question, 'How will you incorporate the strategies discussed in this workshop in your own personal professional life?' were coded as 'incorporating self-care'.

There were 36 responses coded as useful, with 35 responses recorded as incorporating self care. Thirty-seven categories were developed and coded, reflecting the diversity of responses from participants. The large number of categories reflects the personal nature of the workshop, where each individual gains something different from the experiences of the workshop. In the final analysis, the most frequently cited responses named the following concepts: self-care (26 responses), mindfulness (24 responses), stressful (22 responses), techniques (22 responses), awareness (21 responses) and meditation (20 responses).

Each category is presented in Table 4 along with some quotes to illustrate the voices of participants

\section{$\underline{\text { Insert table } 4}$}




\section{Discussion}

This workshop was important to the students in our first year cohort in identifying the need to reflect on their current personal and professional supports and helped them find new supports, particularly peer-to-peer support. Although students reported being 'comfortable' with meeting new people in a new environment, the most valuable aspect of the first workshop was the socialisation and networking of the new students. Considering the diversity of the student population (Carolan \& Kruger 2011a; Cullen et al. 2016) we were inspired to explicitly introduce students to each other through something they have in common. In this instance they were all on the same trainline allowing the students to meet someone they may never have spoken to without this exercise. Being on the same trainline meant the students would talk again when travelling to and from university. This offered the opportunity for the student to find support through a peer. Having a sense of connectedness to their peers has been shown to be important in supporting students to not only remain in midwifery but thrive through the three years of study and to evolve into the midwife they dream of becoming (Sidebotham et al. 2015). Reports of personal and professional support increased significantly following the first workshop. These findings highlighted the need for the students to reflect upon their current support systems and encourage them to find new ones due to the sensitive nature of midwifery.

The sensitive nature of midwifery was reflected in the images and sounds of women in labour. These activities were designed to instigate emotions that the students may encounter during their studies in midwifery and later in midwifery practice. Students were significantly more comfortable with these images and sounds at the completion of the workshop. Such an activity prepared the students for the real life often graphic scenarios and case studies that they are exposed to in the first few weeks of semester. The images and sounds drawn from real life women in labour is often in contrast to the students' visions and perceptions of childhood and motherhood that have been shaped, in most, by the media (Carolan \& Kruger 2011a; Cullen et al. 2016). Implementing this workshop prompted students to reflect on their vision of childbirth and facilitated them to consider the sensitive and often challenging nature of childbirth (Fraser \& Hughes 2009). The discussion of the language, images and sounds of women in labour had the potential to cause emotional distress and we wanted students to be aware of this before they were in class or clinical practice. 
The emotional work of midwifery (Hunter 2001) can be challenging, and addressing some of the triggers that may cause distress to the students brought us one step closer to assisting the students to firstly identify the triggers and then to seek support. The students found the opportunity to share opinions and feelings about sensitive issues in midwifery very valuable. Providing a safe environment for these discussions helped the students normalise how they were feeling particularly if they felt confronted or distressed. Other studies (Carolan \& Kruger 2011b; Gray et al. 2012; Green \& Baird 2009) have found students need support to successfully complete midwifery with all the compounding stresses including balancing home, work, study, clinical components and the sensitive issues in midwifery. Students are likely to leave midwifery if they do not have adequate support when feeling overwhelmed, hence it is imperative that midwifery faculties provide support (Green \& Baird 2009). Suggested support includes making students aware of university counselling services and peer support (Carolan \& Kruger 2011b; Green \& Baird 2009). Our workshops explicitly informed the students of how to access free university (on site) counselling services, actively promoted peer-topeer support and provided insight to differing student opinions on sensitive issues.

Understanding different opinions was discussed as a valuable learning experience for the new midwifery students in our workshop. Having the opportunity to listen to other's opinions introduced the students to the concept of cultural safety when the views of students are not congruent. Cultural safety requires midwifery students to engage in self reflection on their values attitudes and beliefs (Phiri, Dietsch \& Bonner 2010). Although the workshop did not specifically aim to address cultural safety in midwifery practice, the self-reflection activity allowed students to begin to understand differing opinions which is a useful tool for beginning practitioners and may lead to increased cultural safety and enhanced empathy in the future. Empathy levels have been measured in first year undergraduate midwifery students and found to be quite low increasing over the three year duration of the course (McKenna et al. 2011). Our introductory workshop for first year midwifery students may help develop empathy as students unpick each other's opinions and begin to 'normalise' these opinions as found in our evaluation. However the aim of the workshop was not to develop empathy in students but to foster self-care strategies, particularly when faced with the sensitive nature of midwifery.

The second workshop was rated as very useful by the students and enabled them to develop new self-care strategies. The students overwhelmingly said they would 
incorporate strategies including mindfulness into their personal and professional lives. The experience from a pilot study of midwives and nurses in practice found that taking a positive psychology approach was effective in increasing resilience in individuals (Foureur et al. 2013). Another pilot study explored the introduction of a mindfulness program for first year nursing students and found this was the perfect time to learn new skills in stress management (van der Riet et al. 2015). In our evaluation the students found learning new techniques in meditation, relaxation and self-care useful and they stated they would practise these techniques in order to incorporate them into their everyday personal and professional lives. In addition to caring for themselves, we also found the midwifery students would incorporate mindfulness as a strategy in caring for others, helping them to develop into the caring compassionate midwives they had envisioned. Others have found similar results for first year nursing students who identify the benefits of mindfulness as enhancing their ability to 'be with' (van der Riet et al. 2015). The students appreciated having time to practise the mindfulness and meditative skills in class. Students will be able to practise mindfulness and meditative skills in other classes and use the skills in everyday life.

\section{Limitations}

This evaluation is limited to one cohort of first year Bachelor of Midwifery students in New South Wales, Australia. The project measured and explored the value and usefulness of introducing two workshops about sensitive issues in midwifery and about fostering self-care and mindfulness in first year midwifery students. Further research is recommended to discover whether these workshops would be warranted for other midwifery student groups.

\section{Conclusion}

Midwifery degrees attract a diverse student population who share a common goal: to be a compassionate, caring midwife who will facilitate positive birth experiences for women and their families. These idealised views are often shattered when faced with the sensitive issues of midwifery and some confronting topics that are discussed early in the degree. This, together with the reality of a demanding study load and clinical practice placements, may lead to students wanting to leave the course. We aimed to prepare students for some of the emotions they may experience when undertaking midwifery through workshops designed to acknowledge and increase personal support systems and engage students in self-care strategies. Students found the workshops useful in order to meet new people and develop new supports. The first workshop was valuable in respecting others opinions, normalising their feelings and learning to discuss 
sensitive issues. The fostering self-care workshop was found to be useful for the students to incorporate self-care strategies, learning to be more mindful, being aware and preparing themselves for stressful situations and practising/using meditation. Through embedding this first year workshop into the curriculum we hope to not only address attrition rates but to facilitate the students' vision to become compassionate, caring, woman-centred midwives who assist women and their families to have a positive transition to parenthood even when faced with some harsh realities of midwifery practice. 


\section{References}

Carolan, M. \& Kruger, G. 2011a, 'Undertaking midwifery studies: Commencing students' views', Midwifery, vol. 27, no. 5, pp. 642-7.

Carolan, M.C. \& Kruger, G.B. 2011b, 'Concerns among first year midwifery students: Towards addressing attrition rates', Contemporary Nurse, vol. 38, no. 1-2, pp. 139-47.

Cullen, D., Sidebotham, M., Gamble, J. \& Fenwick, J. 2016, 'Young student's motivations to choose an undergraduate midwifery program', Women and Birth, vol. 29, no. 3, pp. 234-9.

Cummins, A.M., Catling, C., Hogan, R. \& Homer, C.S.E. 2014, 'Addressing culture shock in first year midwifery students: Maximising the initial clinical experience', Women and Birth, vol. 27, no. 4, pp. 271-5.

DeJoy, S.B. 2010, '"Midwives Are Nice, But ...": Perceptions of Midwifery and Childbirth in an Undergraduate Class', Journal of Midwifery \& Women's Health, vol. 55, no. 2, pp. 117-23.

Foureur, M., Besley, K., Burton, G., Yu, N. \& Crisp, J. 2013, 'Enhancing the resilience of nurses and midwives: Pilot of a mindfulness-based program for increased health, sense of coherence and decreased depression, anxiety and stress', Contemporary Nurse: A Journal for the Australian Nursing Profession, vol. 45, no. 1, pp. 114-25.

Fraser, D.M. \& Hughes, A.J. 2009, 'Perceptions of motherhood: The effect of experience and knowledge on midwifery students', Midwifery, vol. 25, no. 3, pp. 307-16.

Gray, J.E., Leap, N., Sheehy, A. \& Homer, C.S. 2012, 'The 'follow-through'experience in three-year Bachelor of Midwifery programs in Australia: A survey of students', Nurse Education in Practice, vol. 12, no. 5, pp. 258-63.

Green, S. \& Baird, K. 2009, 'An exploratory, comparative study investigating attrition and retention of student midwives', Midwifery, vol. 25, no. 1, pp. 79-87.

Hunter, B. 2001, 'Emotion work in midwifery: a review of current knowledge', Journal of Advanced Nursing, vol. 34, no. 4, pp. 436-44.

Kern, M.L., Waters, L.E., Adler, A. \& White, M.A. 2015, 'A multidimensional approach to measuring well-being in students: Application of the PERMA framework', The Journal of Positive Psychology, vol. 10, no. 3, pp. 262-71.

McKenna, L., Boyle, M., Brown, T., Williams, B., Molloy, A., Lewis, B. \& Molloy, L. 2011, 'Levels of empathy in undergraduate midwifery students: An Australian cross-sectional study', Women and Birth, vol. 24, no. 2, pp. 80-4.

Minichiello, V., Sullivan, G., Greenwood, K. \& Axford, R. 2004, Research Methods for Nursing and Health Science, 2nd edn, Prentice Hall, Frenchs Forest.

Phiri, J., Dietsch, E. \& Bonner, A. 2010, 'Cultural safety and its importance for Australian midwifery practice', Collegian, vol. 17, no. 3, pp. 105-11.

Seibold, C. 2005, 'The Experiences of a first cohort of Bachelor of Midwifery students, Victoria, Australia ', Australian Midwifery Journal vol. 18, no. 316.

Sidebotham, M., Fenwick, J., Carter, A. \& Gamble, J. 2015, 'Using the five senses of success framework to understand the experiences of midwifery students enroled in an undergraduate degree program', Midwifery, vol. 31, no. 1, pp. 201-7.

van der Riet, P., Rossiter, R., Kirby, D., Dluzewska, T. \& Harmon, C. 2015, 'Piloting a stress management and mindfulness program for undergraduate nursing 
students: Student feedback and lessons learned', Nurse Education Today, vol. 35, no. 1, pp. 44-9.

Williams, J. 2009, Why women choose midwifery: a narrative analysis of motivations and understandings in a group of first-year student midwives, Royal College of Midwives, London, viewed 17th May 2017 2017, <https://www.rcm.org.uk/learning-and-career/learning-andresearch/ebm-articles/why-women-choose-midwifery-a-narrative>.

Yu, N. 2014, Slow Coach, viewed 18th November 2014 2014, <http://www.slowcoachsydney.org/>. 